\title{
High intensity interval training exercise- induced physiological changes and their potential influence on metabolic syndrome clinical biomarkers: a meta-analysis
}

I. Serrablo-Torrejon ${ }^{1,2^{*}+}$, A. Lopez-Valenciano ${ }^{2,3+}$, M. Ayuso², E. Horton ${ }^{1}$, X. Mayo ${ }^{2,3}$, G. Medina-Gomez ${ }^{3}$, G. Liguori ${ }^{4}$ and A. Jimenez $z^{2,3,5}$

\begin{abstract}
Background: Despite the current debate about the effects of high intensity interval training (HIIT), HIIT elicits big morpho-physiological benefit on Metabolic Syndrome (MetS) treatment. However, no review or meta-analysis has compared the effects of HIIT to non-exercising controls in MetS variables. The aim of this study was to determine through a systematic review, the effectiveness of HIIT on MetS clinical variables in adults.

Methods: Studies had to be randomised controlled trials, lasting at least 3 weeks, and compare the effects of HIIT on at least one of the MetS clinical variables [fasting blood glucose (BG), high-density lipoprotein (HDL-C) triglyceride (TG), systolic (SBP) or diastolic blood pressure (DBP) and waist circumference (WC)] compared to a control group. The methodological quality of the studies selected was evaluated using the PEDro scale.

Results: Ten articles fulfilled the selection criteria, with a mean quality score on the PEDro scale of 6.7. Compared with controls, HIIT groups showed significant and relevant reductions in BG $(-0.11 \mathrm{mmol} / \mathrm{L})$, SBP $(-4.44 \mathrm{mmHg})$, $\operatorname{DBP}(-3.60 \mathrm{mmHg})$, and $\mathrm{WC}(-2.26 \mathrm{~cm})$. Otherwise, a slight increase was observed in HDL-C $(+0.02 \mathrm{mmol} / \mathrm{L})$. HIIT did not produce any significant changes in TG $(-1.29 \mathrm{mmol} / \mathrm{L})$.

Conclusions: HIIT improves certain clinical aspects in people with MetS (BG, SBP, DBP and WC) compared to people with MetS who do not perform physical exercise. Plausible physiological changes of HIIT interventions might be related with large skeletal muscle mass implication, improvements in the vasomotor control, better baroreflex control, reduction of the total peripheral resistance, increases in excess post-exercise oxygen consumption, and changes in appetite and satiety mechanisms.
\end{abstract}

Keywords: High intensity interval training, Metabolic syndrome, Meta-analysis

\footnotetext{
* Correspondence: serrabli@uni.coventry.ac.uk

${ }^{\dagger}$ I. Serrablo-Torrejon and A. Lopez-Valenciano contributed equally to this work.

'Faculty Research Centre for Sport, Exercise \& Life Sciences, School of Health

and Life Sciences, Coventry University, Coventry, UK

${ }^{2}$ GO fit LAB, Av. Islas de Filipinas, 7, 28003 Madrid, Spain

Full list of author information is available at the end of the article
}

(c) The Author(s). 2020 Open Access This article is licensed under a Creative Commons Attribution 4.0 International License, which permits use, sharing, adaptation, distribution and reproduction in any medium or format, as long as you give appropriate credit to the original author(s) and the source, provide a link to the Creative Commons licence, and indicate if changes were made. The images or other third party material in this article are included in the article's Creative Commons licence, unless indicated otherwise in a credit line to the material. If material is not included in the article's Creative Commons licence and your intended use is not permitted by statutory regulation or exceeds the permitted use, you will need to obtain permission directly from the copyright holder. To view a copy of this licence, visit http://creativecommons.org/licenses/by/4.0/ The Creative Commons Public Domain Dedication waiver (http://creativecommons.org/publicdomain/zero/1.0/) applies to the data made available in this article, unless otherwise stated in a credit line to the data. 


\section{Background}

Despite the efforts from national and international bodies to promote healthy behaviours and prevent physical inactivity, global physical inactivity levels have failed to come down over the last decade [1, 2]. In 2016, global physical inactivity prevalence was $27.5 \%$, which means that more than one of every four adults do not meet the minimum recommended physical activity levels [3, 4]. Not meeting the recommended levels of physical activity increases the risk of developing chronic diseases such as obesity, hypertension, type 2 diabetes, osteoporosis, and cancer, and increases the mortality risk $[5,6]$.

Within these diseases, Metabolic Syndrome (MetS) has one of the highest mortality rates [7]. MetS is defined as a cluster of cardiovascular risk factors that includes elevated blood glucose (BG), low high-density lipoprotein (HDL-C), high triglycerides (TG) levels, high systolic blood pressure (SBP), high diastolic blood pressure (DBP) and increased waist circumference (WC) [8]. It is further agreed that an individual is diagnosed with MetS when three or more of the aforementioned risk factors are present. Even though MetS is responsible for many deaths, it is a condition that is underdiagnosed and therefore undertreated because it is largely asymptomatic [9]. For example, the reported prevalence of MetS in the United States is $35 \%$, however this figure rises to $50 \%$ for adults aged 60 and over $[10,11]$. In this regard, MetS is a strong predictor of cardiovascular and allcause mortality. Thus, it is imperative to diagnose and treat individuals with metabolic syndrome effectively [12-14].

The standard treatment for MetS is to prescribe pharmaceuticals for the treatment of the individual risk factors (i.e. hypertension, diabetes, etc), which also brings potentially adverse side effects, such as gastrointestinal problems, arrhythmias, weight gain, insomnia, dizziness, asthenia, etc. $[15,16]$. However, evidence suggests that an appropriate lifestyle can help manage and prevent MetS and its associated factors [17]. More specifically, daily physical activity (PA) has been shown to reduce most of the MetS risk factors, and therefore MetS itself $[18,19]$. Thus, exercise prescription should be considered as a non-pharmacological, non-invasive, first-line, low-cost treatment to improve MetS. There is evidence that shows strong links between exercise and reducing the prevalence of MetS [20], likely a result of increased caloric expenditure and structural changes in muscle $[21,22]$.

Lack of time is often cited as one of the main reasons not to meet the recommended PA levels [23]. Because of the time constraints, there is a growing interest in developing alternative approaches to exercise that require shorter work times and lower training volumes, yet still elicit physiological benefits similar to more traditional exercise bouts.
High Intensity Interval Training (HIIT) on MetS is believed to be one of the most time-efficient training modes that have been recently developed [24]. HIIT consists of bouts of exercise at high intensity interspersed by periods of active/passive recovery. HIIT training combinations, by modifying work and rest ratios, are infinite. With shorter training times, it has been suggested that HIIT training can induce similar benefits as prolonged training on cardiorespiratory fitness and muscle oxidative capacity $[25,26]$.

Nonetheless the prescription of HIIT to inactive individuals that suffer MetS is not without controversy [27], as HIIT is deemed unsafe by some authors. In the literature, we find that after $24 \mathrm{~h}$ after a bout of HIIT in patients with cardiometabolic diseases, the adverse responses (cardiac arrest or myocardial infarction) to HIIT is around $8 \%$ (most of them were mild in nature), which is slightly higher than seen after Moderate Intensity Continuous Training (MICT) [28]. Although caution must be taken before high intensity training in people with cardiovascular diseases, recent systematic reviews of randomised controlled trials found that the number of adverse events is low [29,30] and these percentages are much lower in asymptomatic people [31,32], so this type of training could classified as safe under supervision. In addition to suggesting that HIIT is potentially less safe than MICT, some authors believe that HIIT will not have a public health impact because it is too demanding, eliciting low enjoyment levels and that current inactive people will not adhere to HIIT on the long term, only active individuals will take up this mode of exercise [27]. On the other hand, those that points out HIIT as a promising opportunity to promote a more active behaviour, say that the traditional forms of exercise, including MICT, have been a failure [27]. In regard to behaviour, several studies have reported that HIIT usually offers more enjoyment and affective responses both during and immediately after exercise [33]. Therefore, HIIT may be an alternative to MICT for inducing positive physiological adaptations [28] and doing so in a more enjoyable way [27].

For these reasons there has been an increase in articles published on the effects HIIT has on populations with various chronic diseases, including MetS. Recent studies seem to find that HIIT elicits big morpho-physiological benefit on MetS treatment. Previous reviews have compared the effects HIIT and MICT have on MetS and in single cardiovascular risk factors, and all are in agreement that HIIT can produce similar health benefits in MetS components compared to MICT, yet in a shorter time frame [34-36]. However, to date, no review or metaanalysis has compared the effects of HIIT to nonexercising controls in MetS variables. 
Therefore, the purpose of this meta-analysis is to review the literature of randomised controlled trials (RCT) in regard to the effectiveness of HIIT interventions on MetS variables (BG, HDL-C, TG, SBP, DBP, and WC) in adults compared to non-exercise controls.

\section{Methods}

In order to accomplish our objectives, this review followed the Preferred Reporting Items for Systematic Reviews and Meta-Analyses (PRISMA) guidelines [37]. PRISMA checklist can be found in Appendix 1.

\section{Study selection and eligibility criteria}

To be included in the meta-analysis, each study had to fulfil the following criteria: a) Studies had to be randomised controlled trials (RCT), lasting at least 3 weeks, that analysed the effects of HIIT in at least one variable of MetS (BG, HDL-C, TG, SBP, DBP and/or WC) in people with MetS [8] (Table 1); b) all participants in the studies had to be aged $\geq 18$ years; c) sample size in the post-test had to be higher than 4 participants per group; d) studies had to include a non-exercising control group; e) studies had to report enough statistical data to calculate the effect sizes; f) studies had to be published before January 2020; and g) studies had to be written in English or Spanish. Animal studies, review articles, acute exercise studies, and nonrandomised-controlled trials were excluded.

\section{Search strategy}

Potential studies were identified using a systematic search process. First, the following bibliographical databases were searched: Cochrane Library, Embase, PubMed, Sportdiscus, and Web of Science, with the following search terms included in Boolean search strategies: (metabolic syndrome [tiab] OR metabolic syndrome [mesh] OR comorbidities [tiab] OR comorbidities [mesh] OR cardiometabolic disease [tiab] OR cardiometabolic disease [mesh]) AND (HIIT [tiab] OR HIIT [mesh] OR high intensity interval training [tiab] OR high intensity interval training [mesh] OR interval training [tiab] OR interval training [mesh]).
The search was limited to publication dates (to "December $31^{\text {st }}, 2019$ "). The reference lists of the studies recovered were hand searched to identify potentially eligible studies not captured by the electronic searches. Two reviewers (I.S.T. and M.A.C.) independently screened the title, abstract and reference list of each study to locate potentially relevant studies, and once hard copies of the screened documents were obtained. The reviewers also attempted to identify articles that met the selection criteria. A third external reviewer (A.L.V.) was consulted to resolve discrepancies regarding the selection process.

\section{Data extraction and quality assessment}

To guarantee the maximum objectivity possible, a codebook was produced that specified the standards followed in coding each of the characteristics of the studies. The outcome measures were BG $(\mathrm{mmol} / \mathrm{L}), \mathrm{HDL}-\mathrm{C}(\mathrm{mmol} / \mathrm{L})$, TG (mg/dL). SBP (mmHg), DBP (mmHg), and WC (cm).

A complete assessment of the level of risk of bias of the included studies was made following The Cochrane Collaboration's tool for assessing the risk of bias in randomised trials [38]. The methodological quality of the studies selected was evaluated using the Physiotherapy Evidence Database Scale (PEDro) [39]. A total score out of 10 is derived for each study, adding the criteria that are achieved, a PEDro score ranging from 6 to 10 is indicative of high quality, 4-5 indicates fair quality, and scores of 3 or less indicate poor quality [40]. To assess the inter-coder reliability of the coding process, two researchers coded all the selected studies, including methodological quality assessment and risk of bias. For the quantitative moderator variables, intra-class correlation coefficients (ICCs) were calculated, whereas for the qualitative moderator variables, Cohen's kappa coefficients were applied. On average, the ICC was 0.96 (range 0.93-1.0) and the kappa coefficient was 0.98 (range 0.95-1.0), which can be considered highly satisfactory [41]. The inconsistencies between the two coders were resolved by consensus or by consulting with a third reviewer. The datasets used and/or analysed during the current study are available from the corresponding author on reasonable request.

Table 1 Clinical cut off values of Metabolic Syndrome components

\begin{tabular}{ll}
\hline Component & Clinical Cut Off Value \\
\hline Blood Glucose OR (taking anti diabetic medication) & $>100 \mathrm{mg} / \mathrm{dL}$ \\
High-density lipoprotein OR (taking medication for reduced HDL-C) & $<40 \mathrm{mg} / \mathrm{dL}$ in males; $<50 \mathrm{mg} / \mathrm{dL}$ in females \\
Triglycerides & $>150 \mathrm{mg} / \mathrm{dL}$ \\
Systolic Blood Pressure / Diastolic Blood Pressure OR (taking anti-hypertensive medication) & $>130 \mathrm{mmHg} />85 \mathrm{mmHg}$ \\
Waist Circumference & $>102 \mathrm{~cm}$ in males; $>88 \mathrm{~cm}$ in females
\end{tabular}

${ }^{a}$ It is recommended that the International Diabetes Federation cut points be used for non-Europeans and either the International Diabetes Federation cut points used for people of European origin until more data are available 


\section{Statistical analysis}

All outcomes were reported as means and standard deviations (SD). The standardized mean differences (SMD) were calculated to determine Cohen's d for each study. For each of the five outcome measures (BG, HDL-C, TG, SBP, DBP and WC), an effect size was calculated as the average difference between the post-test and pre-test change scores of the experimental and control groups: $D$ $=\left(m_{\text {Post }}^{E}-m_{\text {Pre }}^{E}\right)-\left(m_{\text {Post }}^{C}-m_{\text {Pre }}^{C}\right)$ [42]. Negative D values indicated a better result for the intervention group (INT) than for the control one. Separate meta-analyses were performed for each outcome measure. For each, an average effect size $\left(D_{+}\right)$and a $95 \%$ CI were calculated by assuming a fixed-effects model, with the inverse variance as the weighting factor [43]. Heterogeneity of the effect sizes across studies was assessed by means of Cochrane
$Q$ statistic and the $I^{2}$ index. A forest plot was also constructed for each meta-analysis. Lack of homogeneity was considered for Cochrane $Q$ tests with $p<0.10$ and/ or for $I^{2}$ indices. The forest plots were carried out with the Review Manager (RevMan) software package (version 5.5 for OSX, The Nordic Cochrane Centre, The Cochrane Collaboration, 2014, Copenhagen, Denmark).

\section{Results}

\section{Study selection}

Our search strategy resulted in 2487 references. Of these, 954 were removed as duplicates after the first screening, and 1482 references were removed based on the title and abstract. Two other studies had duplicated data, 12 were not randomised controlled trials, 14 studies did not apply HIIT in their interventions, 10 did not include participants

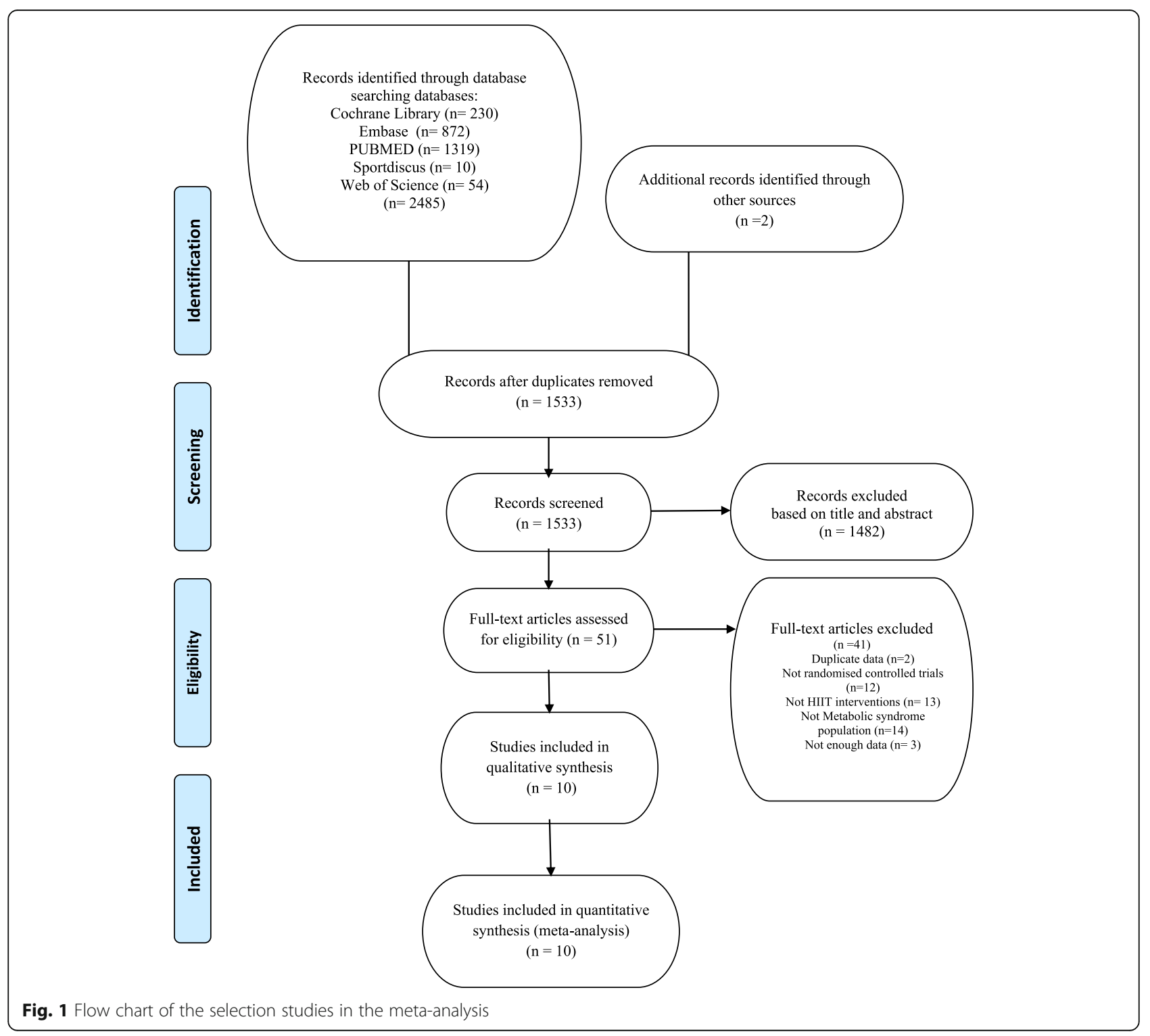


with METS, and 3 did not have enough data to calculate effect size. Finally, 10 studies that met the selection criteria were identified [44-53]. Figure 1 shows the flow chart of the selection process of studies.

\section{Descriptive characteristics of the studies}

The main characteristics of each of the studies are presented in Table 2 . The studies selected were conducted between 2007 and 2018. Six studies were carried out in Spain, two in Norway, one in Iran, and one in Brazil. The total sample size was 355 in the HIIT intervention groups and 174 in the control groups. Two studies included only men [51], one study included only women [44] and eight trials included men and women [45-50, 52, 53]. The length of the HIIT interventions ranged from 3 to 24 weeks and the weekly training frequency was 3 sessions

Table 2 Characteristics of the studies included in the meta-analysis

\begin{tabular}{|c|c|c|c|c|c|}
\hline Paper/Country & $\begin{array}{l}\text { Participants/ } \\
\text { Gender }\end{array}$ & $\begin{array}{l}\text { Duration } \\
\text { (Weeks) }\end{array}$ & $\begin{array}{l}\text { Frequency } \\
\text { (Days/week) }\end{array}$ & Exercise training characteristics & Outcome \\
\hline $\begin{array}{l}\text { Alvarez et al. } \\
2018 \text { [44] } \\
\text { (Brazil) }\end{array}$ & $\begin{array}{l}\text { HIIT } \\
\text { DYSHG: } 12 \\
\text { CG: } 12 \\
\text { Female }\end{array}$ & 16 & 3 & $\begin{array}{l}8 \text { to } 14 \text { bouts of } 30 \text { to } 58 \text { s of jogging/ } \\
\text { running at } 90 \% \text { HRreserve, interspersed } \\
\text { with recovery periods at } 70 \% \text { HRreserve } \\
\text { that lasted between } 120 \text { s and } 96 \text { s. The } \\
\text { number of bouts and the duration of } \\
\text { each interval increased every week, } \\
\text { duration of the recovery periods } \\
\text { shortened every week. }\end{array}$ & $\begin{array}{l}\text { HIIT improved BG, HDL-C, TG, BP, } \\
\text { TC, LDL-C, endurance performance, } \\
\text { body composition and in women } \\
\text { in the DYSHG group. }\end{array}$ \\
\hline
\end{tabular}

\begin{tabular}{|c|c|c|c|c|}
\hline $\begin{array}{l}\text { Morales Palomo } \\
\text { et al. } 2017 \text { [45] } \\
\text { (Spain) }\end{array}$ & $\begin{array}{l}\text { HIIT (TRAIN): } 23 \\
\text { CG: } 26 \\
\text { Mixed }\end{array}$ & 16 & 3 & $\begin{array}{l}4 \text { bouts of } 4 \text { min of pedalling at } 90 \% \text { of } \\
\text { maximal HR interspersed with 3-min } \\
\text { active recovery periods at } 70 \% \\
\text { maximal HR. }\end{array}$ \\
\hline $\begin{array}{l}\text { Morales Palomo } \\
\text { et al. } 2019 \text { [46] } \\
\text { (Spain) }\end{array}$ & $\begin{array}{l}\text { HIIT }(4 H \| I T): 32 \\
\text { CG: } 22 \\
\text { Mixed }\end{array}$ & 16 & 3 & $\begin{array}{l}4 \text { bouts of } 4 \text { min of pedalling at } 90 \% \\
\text { of maximal } H R \text { interspersed with } 3 \text {-min } \\
\text { active recovery periods at } 70 \% \text { maximal } \\
\text { HR. }\end{array}$ \\
\hline $\begin{array}{l}\text { Mora Rodriguez } \\
\text { et al. } 2017 \text { [47] } \\
\text { (Spain) }\end{array}$ & $\begin{array}{l}\text { HIIT (TRAIN): } 23 \\
\text { CG: } 23 \\
\text { Mixed }\end{array}$ & 24 & 3 & $\begin{array}{l}4 \text { bouts of } 4 \text { min of pedalling at } 90 \% \text { of } \\
\text { maximal HR interspersed with 3-min } \\
\text { active recovery periods at } 70 \% \\
\text { maximal HR. }\end{array}$ \\
\hline $\begin{array}{l}\text { Mora Rodriguez } \\
\text { et al. 2018a [48] } \\
\text { (Spain) }\end{array}$ & $\begin{array}{l}\text { HIIT (TRAIN): } 18 \\
\text { CG: } 16 \\
\text { Mixed }\end{array}$ & 24 & 3 & $\begin{array}{l}4 \text { bouts of } 4 \text { min of pedalling at } 90 \% \\
\text { of maximal } H R \text { interspersed with } 3 \text {-min } \\
\text { active recovery periods at } 70 \% \text { maximal } \\
\text { HR. }\end{array}$ \\
\hline $\begin{array}{l}\text { Mora Rodriguez } \\
\text { et al. 2018b [49] } \\
\text { (Spain) }\end{array}$ & $\begin{array}{l}\text { HIIT (TRAIN): } 23 \\
\text { CG: } 22 \\
\text { Mixed }\end{array}$ & 16 & 3 & $\begin{array}{l}4 \text { bouts of } 4 \text { min of pedalling at } 90 \% \text { of } \\
\text { maximal HR interspersed with 3-min } \\
\text { active recovery periods at } 70 \% \text { maximal } \\
\text { HR. }\end{array}$ \\
\hline $\begin{array}{l}\text { Mora Rodríguez } \\
\text { et al. } 2019 \text { [50] } \\
\text { (Spain) }\end{array}$ & $\begin{array}{l}\text { HIIT (TRAIN): } 76 \\
\text { CG: } 20 \\
\text { Mixed }\end{array}$ & 16 & 3 & $\begin{array}{l}\text { Twenty minutes continuous at } 70 \% \\
\text { of HRmax followed by } 4 \text { bouts of } 3 \text { min } \\
\text { of walking/running at } 90 \% \text { of HRmax } \\
\text { interspersed with a } 3 \text {-min active recovery } \\
\text { at } 70 \% \text { of HRmax between intervals. }\end{array}$ \\
\hline $\begin{array}{l}\text { Sari-Sarraf et al. } \\
2015 \text { [53] } \\
\text { (Iran) }\end{array}$ & $\begin{array}{l}\text { HIIT }(H \| I T 2): 11 \\
\text { CG: } 11 \\
\text { Male }\end{array}$ & 16 & 3 & $\begin{array}{l}\text { HIIT2: } 5 \text { bouts of } 2 \text { min cycling with } \\
\text { 1-min recovery utilizing undulating } \\
\left.\text { intensities ( } 80-100 \% V_{2} O_{2 \text { peak }}\right) \text {. }\end{array}$ \\
\hline $\begin{array}{l}\text { Stensvold et al. } \\
2010 \text { [51] } \\
\text { (Norway) }\end{array}$ & $\begin{array}{l}\text { HIIT (AIT): } 11 \\
\text { CG: } 11 \\
\text { Mixed }\end{array}$ & 12 & 5 & $\begin{array}{l}4 \text { min intervals of walking/running at } \\
90 \% \text { of HRmax interspersed with } 3 \text { min } \\
\text { active recovery periods at } 70 \% \text { of } \\
\text { HRmax. }\end{array}$ \\
\hline $\begin{array}{l}\text { Tjønna et al. } \\
2008 \text { [52] } \\
\text { (Norway) }\end{array}$ & $\begin{array}{l}\text { HIIT (AIT): } 11 \\
\text { CG: } 11 \\
\text { Mixed }\end{array}$ & 16 & 4 & $\begin{array}{l}4 \text { bouts of } 4 \text { min of pedalling at } 90 \% \\
\text { of maximal HR interspersed with 3-min } \\
\text { active recovery periods at } 70 \% \\
\text { maximal HR. }\end{array}$ \\
\hline
\end{tabular}

HIIT reduced $B G, S B P, D B P, W C$, body weight and BMI. TG levels were not affected by training.

HIIT significantly reduced body weight, WC and MAP. BG, HDL-C, TG levels were not changed significantly.

HIIT resulted in a significant decrease in WC and mean arterial blood pressure No significant changes in BG, HDL-C and TG levels in HIIT group.

HIIT resulted in a significant reduction in body weight, percentage of body fat, WC and MAP. HIIT did not elicit changes in TG, BG and HDL-C.

HIIT resulted in significant decrease in SBP, DBP and WC. No significant changes in TG levels in HIIT group.

HIIT resulted in significant decrease in BG, WC and MAP. No significant changes in TG levels in HIIT group.

HIIT resulted in significant decrease in, BG, TG, SBP, DBP and WC. No significant changes in HDL-C levels in HIIT group.

HIIT decreased SBP and DBP

HIIT resulted in significant decrease in DBP, SBP, and WC. HDL-C significantly increased in HIIT group. No significant changes in TG and BG levels in HIIT group.

BG Blood glucose, BP Blood Pressure, BMI Body Mass Index, CG Control group, DBP Diastolic blood pressure, DYSHG Dyslipidemia and high blood glucose, HBA1C Haemoglobin A1c, HDL-C High-density lipoprotein, HR Heart rate, HRpeak Heart rate peak, HRreserve Heart rate reserve, HIIT High intensity interval training, $L D L-C$ Low-density lipoprotein, MAP Mean Arterial Pressure, MICT Moderate intensity continuous training, SBP Systolic blood pressure, TC Total Cholesterol, TG Triglycerides, $V_{2 p e a k}$ Peak oxygen uptake, WC Waist circumference 


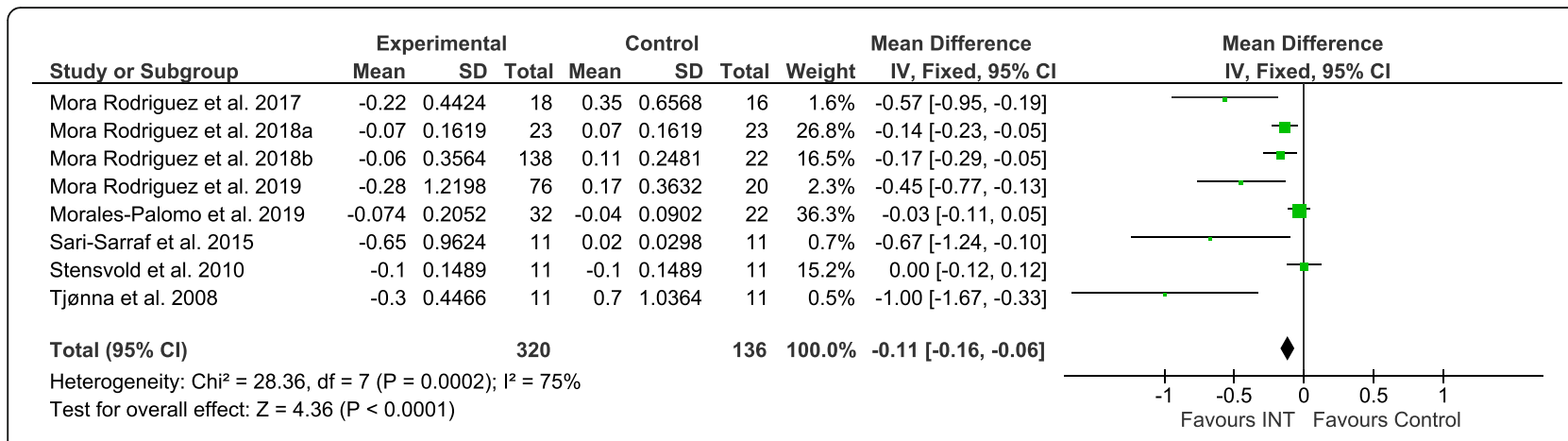

Fig. 2 Forest plot of mean difference in blood glucose (BG) of studies included

per week for 9 trials [44-51], 4 sessions per week in one trial [53] and 5 sessions per week in another trial [54]. Type of exercise was cycling in 7 trials $[45-49,51,53]$ and walking/running on a treadmill in 3 trials [44, 50, 52].

\section{Quality of the selected studies}

The mean score obtained with the PEDro quality scale was 6.7 (minimum score being 5, and the maximum score being 7, higher scores indicating better quality). All of the studies stated the eligibility criteria. Nine studies had the participants randomly allocated to groups, and all had both groups matched at baseline. No studies performed blinding of any kind to the subjects and/or consultants that measure at least one variable. All studies reported results of between-groups statistical analysis and provided point estimates for effect size. PEDro scale of each study can be found in Appendix 2.

\section{Risk of bias}

The risk of bias was assessed with the Cochrane Risk of Bias tool. The risk of bias assessment results can be observed in Appendix 2. According to the Cochrane risk of bias tool, most items (60\%) were classified as low risk of bias.

\section{Effect sizes}

Figures 2, 3, 4, 5, 6 and 7 show the main results and forest plots for each of the meta-analyses. Compared with control groups, HIIT groups showed significant reductions in BG $\left[D_{+}=-0.11 \mathrm{mmol} / \mathrm{L}(95 \% \mathrm{CI}:-0.16\right.$ to 0.06); $p<0.0001$; SMD: -0.56 (95\% CI: -0.77 to -0.34 ). Fig. 2.], SBP $\left[D_{+}=-4.44 \mathrm{mmHg}(95 \% \mathrm{CI}:-6.82\right.$ to 2.06); $p=0.0003$; SMD: -0.48 (95\% CI:-0.75 to -0.20 ). Fig. 3.], DBP $\left[D_{+}=-3.60 \mathrm{mmHg}(95 \% \mathrm{CI}:-5.43\right.$ to 1.78); $p=0.0001$; SMD: -0.49 (95\% CI:-0.76 to -0.21 ). Fig. 4.], and WC $\left[D_{+}=-2.26 \mathrm{~cm}(95 \% \mathrm{CI}:-3.12\right.$ to 1.46); $p<0.00001$; SMD: -0.44 (95\% CI:-0.65 to -0.23 ). Fig. 5.] However, a significant increase was observed between groups for HDL-C $\left[D_{+}=0.02 \mathrm{mmol} / \mathrm{L}\right.$ (95\% CI: 0.00 to 0.02 ); $p=0.03$; SMD: 0.00 (95\% CI:-0.22 to 0.21 ). Fig. 6]. No differences were found in TG $\left[D_{+}=-1.29\right.$ mg/dL (95\% CI:: -3.83 to 1.25$) ; p=0.32$; SMD: -0.13 (95\% CI:-0.35 to 0.09). Fig. 7].

\section{Discussion}

The primary finding of this meta-analysis was that HIIT improved BG, SBP, DBP and WC in individuals with MetS, however HDL-C increase slightly and it did not have any effect on TG.

The reduction observed in BG after HIIT might be explained by increases in skeletal muscle mass, blood flow, and insulin receptors, along with increased disposal of glucose in the skeletal muscle, all as a function of the physical exercise [54]. In addition, there is a known increase in skeletal muscle GLUT-4 expression elicited by training [55] which may be greater following HIIT

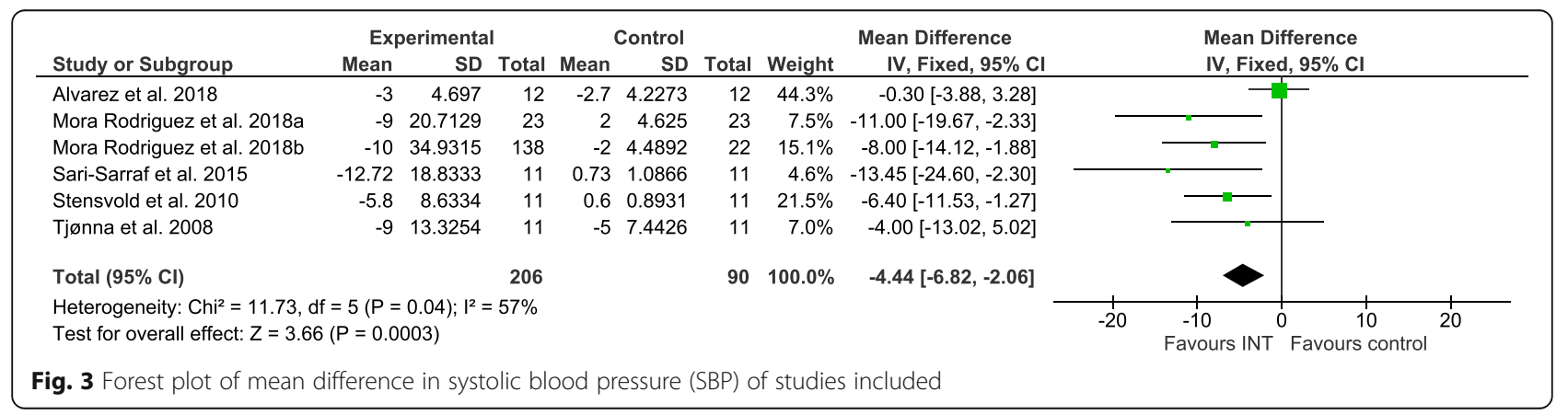




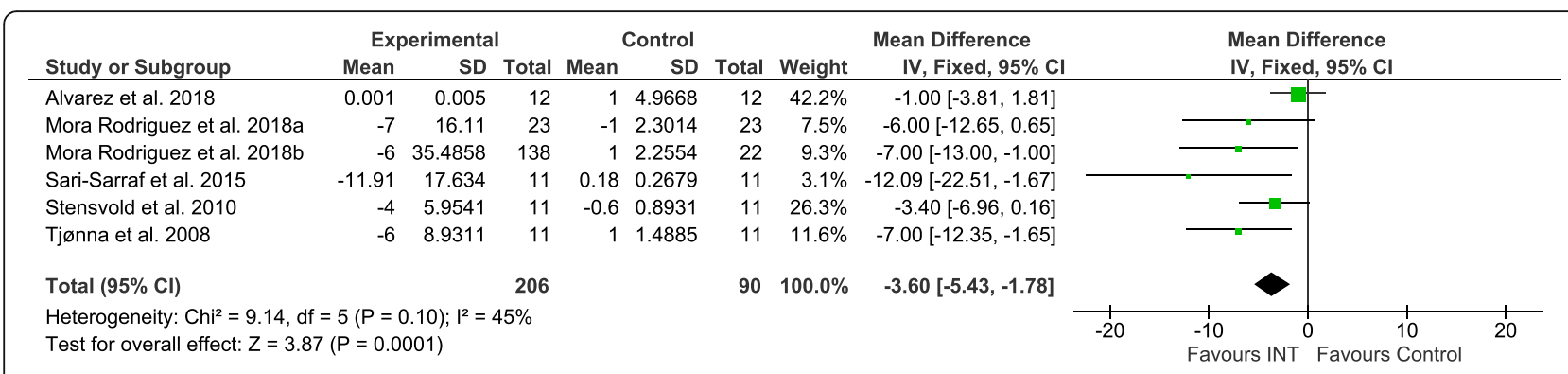

Fig. 4 Forest plot of mean difference in diastolic blood pressure (DBP) of studies included

compared to MICT $[56,57]$. HIIT also results in greater recruitment of type II skeletal muscle fibres [58], which may explain the fact that exercise intensity correlates positively with insulin sensitivity [59], an indication that HIIT could potentially be more effective than MICT in managing BG. In the long term, regular exercise, given the acute inflammatory response to exercise partly mediated by IL- 6 may protect from low-grade inflammation and thus against insulin resistance [60]. Observed effects of aerobic exercise programs on glucose are similar to those reported in HIIT interventions [61].

The HIIT reduction of SBP and DBP $(\sim 4 \mathrm{mmHg})$ has an important clinical impact, since decreases of as little as $2 \mathrm{mmHg}$ reduce the risk of developing coronary artery diseases, myocardial infarction, stroke, and mortality incidence [62-64]. Mechanisms for these reductions in blood pressure are not entirely clear, although enhanced baroreflex control of the sympathetic nerve activity, reduced circulation of catecholamines (norepinephrine), reduced total peripheral resistance, and changes in vasodilator and vasoconstrictor factors are plausible explanations, as these are all elicited by exercise [65-67]. While the role intensity plays on reducing SBP and DBP is not fully understood, compared to other modes of training, HIIT appears to be more potent in reducing SBP and DBP $[68,69]$.
Lastly, HIIT resulted in a significant reduction in WC of $-2.26 \mathrm{~cm}$. It has been previously stated that a reduction of $4 \mathrm{~cm}$ might be clinically relevant [70]. Intraabdominal adipose tissue is a major contributor to MetS [71]. Despite not knowing the precise mechanisms, it has been suggested that the WC reductions might be linked to changes in excess post-exercise oxygen consumption (EPOC), greater fat oxidation, and changes in appetite and satiety mechanisms [72]. EPOC is positively correlated with exercise intensity, thus HIIT has a more powerful effect on EPOC than MICT [73]. Gaitanos et al. [74] suggests that HIIT results in greater fatty acids transport because during the latter stages of HIIT sessions anaerobic glycogenolysis is inhibited, resulting in ATP having to be resynthesised mainly from $\mathrm{PCr}$ degradation and Triglycerol stores. HIIT has also been reported to improve appetite control by reducing average TNF-Alpha, PYY, and Ghrelin concentrations, and increasing GLP-1 [75]. Another meta-analysis [76] reported a $3 \mathrm{~cm}$ reduction in WC induced by MICT in overweight and obese individuals, showing similar decreases in comparison with the HIIT group in that particular metaanalysis and slightly higher than in our study. Nevertheless, the effect of strength training alone on WC has shown to be less potent $(-1.4 \mathrm{~cm})$ [52]

\begin{tabular}{|c|c|c|c|c|c|c|c|c|c|c|}
\hline \multirow[b]{2}{*}{ Study or Subgroup } & \multicolumn{3}{|c|}{ Experimental } & \multicolumn{3}{|c|}{ Control } & \multicolumn{2}{|c|}{ Mean Difference } & \multirow{2}{*}{\multicolumn{2}{|c|}{$\begin{array}{l}\text { Mean Difference } \\
\text { IV, Fixed, } 95 \% \mathrm{CI}\end{array}$}} \\
\hline & Mean & SD & Total & Mean & SD & Total & Weight & IV, Fixed, $95 \% \mathrm{Cl}$ & & \\
\hline Alvarez et al. 2018 & -4.3 & 4.7065 & 12 & -3 & 3.2836 & 12 & $7.0 \%$ & $-1.30[-4.55,1.95]$ & & \\
\hline Mora Rodriguez et al. 2017 & -2 & 4.0021 & 18 & 0.0001 & 0.0002 & 16 & $21.6 \%$ & $-2.00[-3.85,-0.15]$ & & \\
\hline Mora Rodriguez et al. 2018a & -2 & 4.6029 & 23 & 1 & 6.993 & 23 & $6.3 \%$ & $-3.00[-6.42,0.42]$ & & \\
\hline Mora Rodriguez et al. $2018 \mathrm{~b}$ & -2.6 & 15.3772 & 138 & 2.9 & 6.5407 & 22 & $5.3 \%$ & $-5.50[-9.25,-1.75]$ & & \\
\hline Mora Rodriguez et al. 2019 & -1 & 4.3565 & 76 & -2 & 4.2526 & 20 & $16.7 \%$ & $1.00[-1.11,3.11]$ & & \\
\hline Morales-Palomo et al. 2019 & -2.1 & 5.7975 & 32 & 1.8 & 4.0403 & 22 & $10.7 \%$ & $-3.90[-6.52,-1.28]$ & & \\
\hline Sari-Sarraf et al. 2015 & -3.44 & 5.0933 & 11 & 0.14 & 0.2084 & 11 & $8.1 \%$ & $-3.58[-6.59,-0.57]$ & & \\
\hline Stensvold et al. 2010 & -1.3 & 1.9248 & 11 & 1.7 & 2.517 & 11 & $21.1 \%$ & $-3.00[-4.87,-1.13]$ & & \\
\hline Tjønna et al. 2008 & -5 & 7.403 & 11 & -2.3 & 3.4236 & 11 & $3.2 \%$ & $-2.70[-7.52,2.12]$ & & \\
\hline Total $(95 \% \mathrm{Cl})$ & & & 332 & & & 148 & $100.0 \%$ & $-2.26[-3.12,-1.40]$ & & \\
\hline $\begin{array}{l}\text { Heterogeneity: } \text { Chi }^{2}=15.54, d \\
\text { Test for overall effect: } Z=5.16\end{array}$ & $\begin{array}{l}=8(P= \\
(P<0.0\end{array}$ & $\begin{array}{l}=0.05) ; 1^{2}= \\
0001)\end{array}$ & $=49 \%$ & & & & & & $\begin{array}{lll}-4 & -2 & 0 \\
\text { Favours INT }\end{array}$ & 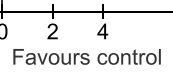 \\
\hline
\end{tabular}




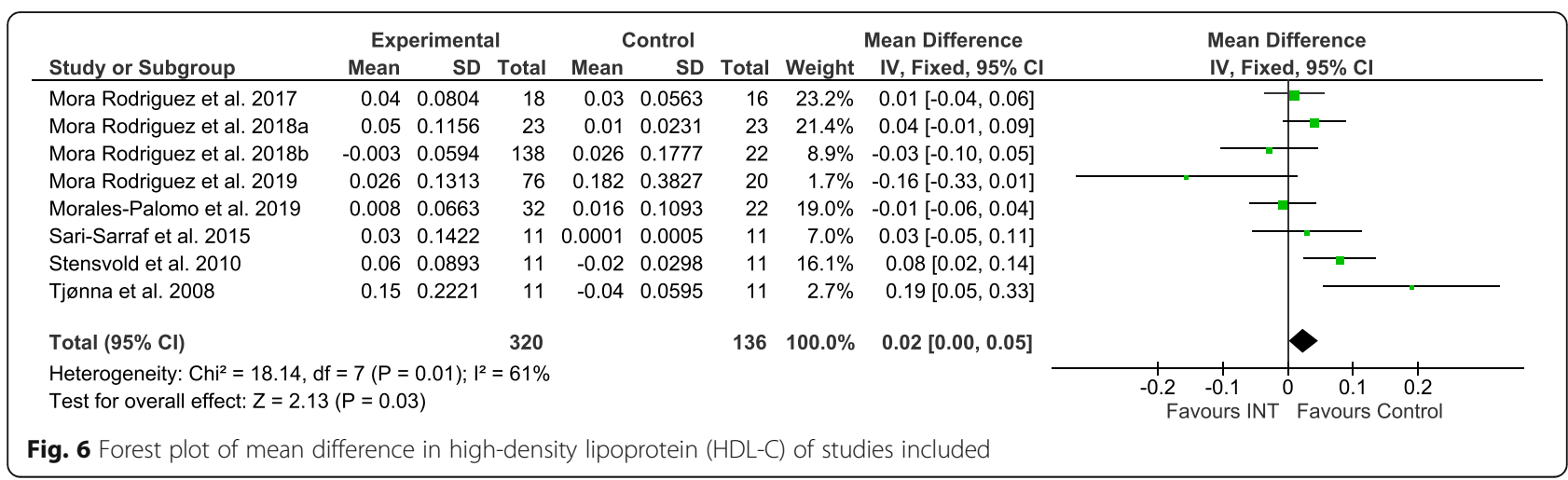

The present meta-analysis showed a slight increase in HDL-C and it did not find any changes in TG, which agrees with a previous meta-analysis [61]. Compared to MICT, HIIT is not superior in altering blood lipids in adults [77], however the mechanisms behind this are not clear and should be addressed in future studies.

The MetS variables that appear to be most sensitive to HIIT are SBP and DBP, thus suggesting that HIIT as a possible first-line treatment for BP. The other MetS variables improved by HIIT improved by the same magnitude as seen with MICT. However, the nature of HIIT is that sessions require less time and often offer greater enjoyment and may therefore be more efficient than MICT.

Despite the mounting evidence that favours using HIIT to improve indices of cardiometabolic health, the potential impact on public health is still subject to debate regarding its safety and adequacy in terms of enjoyment and adherence [27]. Some research in the past has claimed that there is a negative relationship between exercise intensity and affect, thus suggesting this could be detrimental for exercise adherence [78, 79]. However, a recent meta-analysis and systematic review reported that positive affective responses may be obtained from HIIT [33], the rest intervals in HIIT may be responsible for this response by helping reduce discomfort [80]. Recent data show that in healthy non-obese individuals, HIIT is more enjoyable than prolonged continuous exercise due to it being more time-efficient and because of the repeated stimulus changes [81]. On overweight individuals, HIIT is as enjoyable as MICT and with high adherence rates while being performed unsupervised [82]. Also, HIIT appears to become more enjoyable as the training advances, while MICT enjoyment levels remain unchanged as the weeks progress [83], suggesting that in the long term, HIIT appears to be a more suitable mode of exercise. In this meta-analysis there was no drop out difference between control and intervention groups. Data regarding safety of HIIT against MICT shows there are slightly more adverse events following HIIT sessions than MICT sessions [28]. However, a small sample size was employed, thus further research is needed to assess safety of HIIT. Future research should, therefore, focus on optimal training thresholds for HIIT that are effective, enjoyable, and feasible outside to ensure the greatest public health impact.

\section{Limitations}

There are a number of limitations that may affect this meta-analysis that should be taken into consideration. First of all, the sample size of each included study was small, and some scientific criteria were not indicated in some studies, such as lack of follow-up and control of the group activities in the non-exercise groups. Other limitations were that studies employed heterogeneous HIIT protocols, with different duration of bouts and different modes of exercise.

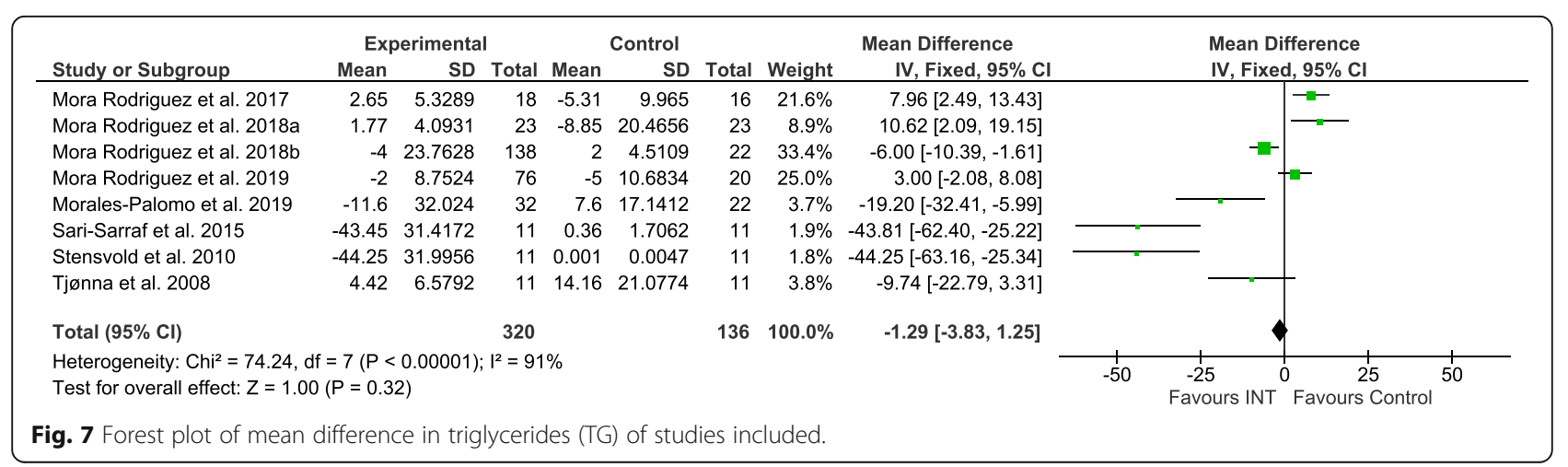




\section{Conclusions}

HIIT interventions showed significant physiological benefits for BG, SBP, DBP and WC reductions, potentially linked with changes in skeletal muscle's oxidative capacity, arterial peripheral resistance, and EPOC. However, no significant differences were observed between experimental and control groups for TG and HDL-C increased in a non-relevant way. Therefore, HIIT has the potential to have a public health impact on critical components of the metabolic syndrome. In addition, the reduced time commitment of HIIT and equal if not better levels of enjoyment may make HIIT even better than MICT on an individual and population level. There is, however, still a need for additional research to determine the causal mechanism producing the beneficial metabolic changes, and also to assess minimum HIIT thresholds in regard to frequency, rest intervals, etc., to produce optimal outcomes.

\section{Appendix 1}

Analysis of the selected studies' methodological quality $(n=10)$.

\begin{tabular}{|c|c|c|c|c|c|c|c|c|c|c|c|c|}
\hline Study & 1 & 2 & 3 & 4 & 5 & 6 & 7 & 8 & 9 & 10 & 11 & Score \\
\hline Alvarez et al. 2018 [44] & + & - & - & + & - & - & - & + & + & + & + & 5 \\
\hline $\begin{array}{l}\text { Morales-Palomo et al. } \\
2017 \text { [45] }\end{array}$ & + & + & + & + & - & - & - & + & + & + & + & 7 \\
\hline $\begin{array}{l}\text { Morales-Palomo et al. } \\
2019 \text { [46] }\end{array}$ & + & + & + & + & - & - & - & + & + & + & + & 7 \\
\hline $\begin{array}{l}\text { Mora Rodriguez et al. } \\
2017 \text { [47] }\end{array}$ & + & + & + & + & - & - & - & + & + & + & + & 7 \\
\hline $\begin{array}{l}\text { Mora Rodriguez et al. } \\
\text { 2018a [48] }\end{array}$ & + & + & + & + & - & - & - & + & + & + & + & 7 \\
\hline $\begin{array}{l}\text { Mora Rodriguez et al. } \\
\text { 2018b [49] }\end{array}$ & + & + & + & + & - & - & - & + & + & + & + & 7 \\
\hline $\begin{array}{l}\text { Mora Rodriguez et al. } \\
2019 \text { [50] }\end{array}$ & + & + & + & + & - & - & - & + & + & + & + & 7 \\
\hline Sari-Sarraf et al. 2015 [53] & + & + & + & + & - & - & - & + & + & + & + & 7 \\
\hline Stensvold et al. 2010 [51] & + & + & + & + & - & - & - & + & + & + & + & 7 \\
\hline Tjønna et al. 2008 [52] & + & + & - & + & - & - & - & + & + & + & + & 6 \\
\hline
\end{tabular}

The numbers of the columns corresponded to the following items of the PEDro scale:

1. Eligibility criteria were specified (not included in score).

2. Subjects were randomly allocated to groups.

3. Allocation was concealed.

4. The groups were similar at baseline regarding the most important prognostic indicator.

5. There was blinding of all subjects.

6. There was blinding of all therapists who administered the therapy.
7. There was blinding of all consultants who measured at least one key outcome.

8. Measures of at least one key outcome were obtained from more than $85 \%$ of the subjects initially allocated to groups.

9. All subjects for whom outcome measures were available received the treatment or control condition as allocated or, where this was not the case, data for at least one key outcome was analysed by intention to treat.

10. The results of between-group statistical comparisons are reported for at least one key outcome.

11. The study provides both point measures and measures of variability for at least one key outcome.

\section{Appendix 2}

Cochrane risk of bias tool of the selected studies $(n=10)$.

\begin{tabular}{lllllll}
\hline Study & $\mathbf{1}$ & $\mathbf{2}$ & $\mathbf{3}$ & $\mathbf{4}$ & $\mathbf{5}$ & $\mathbf{6}$ \\
\hline Alvarez et al. 2018 [44] & + & - & - & - & + & + \\
Morales-Palomo et al. $2017[45]$ & + & + & - & - & + & + \\
Morales-Palomo et al. 2019 [46] & + & + & - & - & + & + \\
Mora Rodriguez et al. 2017 [47] & + & + & - & - & + & + \\
Mora Rodriguez et al. 2018a [48] & + & + & - & - & + & + \\
Mora Rodriguez et al. 2018b [49] & + & + & - & - & + & + \\
Mora Rodriguez et al. 2019 [50] & + & + & - & - & + & + \\
Sari-Sarraf et al. 2015 [53] & + & + & - & - & + & + \\
Stensvold et al. 2010 [51] & + & + & - & - & + & + \\
Tjønna et al. 2008 [52] & + & - & - & - & + & + \\
\hline
\end{tabular}

Risk of bias assessment of the included studies. (+) indicates low risk of bias, (?) indicates unclear risk of bias, (-) indicates high risk of bias:

1. Random sequence generation (Selection bias).

2. Allocation concealment (Selection bias).

3. Blinding (participants and personnel) (Performance bias).

4. Blinding (outcome assessment) (Detection bias).

5. Incomplete outcome data (Attrition bias).

6. Selective reporting (Reporting bias).

\section{Abbreviations}

BG: Blood Glucose; DBP: Diastolic Blood Pressure; HDL-C: High Density Lipoprotein; HIIT: High Intensity Interval Training; MetS: Metabolic Syndrome; MICT: Moderate Intensity Continuous Training; PEDro: Physiotherapy Evidence Database Scale; RCT: Randomised controlled trial; Revman: Review Manager; SBP: Systolic Blood Pressure; TG: Triglycerides; WC: Waist Circumference

Acknowledgements Not applicable. 


\section{Authors' contributions}

IS wrote the manuscript. IS, AL, and MA carried out the review process and statistical analysis, IS, AL, EH, XM participated in the writing and GM, GL, and $\mathrm{AJ}$ in the revision of the work. IS, $\mathrm{AL}$ and $\mathrm{AJ}$ designed the research and supervised the work. All authors read and approved this manuscript.

\section{Funding}

IS is funded by a PhD joint-scholarship from GO fit LAB Ingesport and Coventry University.

\section{Availability of data and materials}

The datasets used and analysed during the current study are available from the corresponding author on reasonable request.

\section{Ethics approval and consent to participate}

Not applicable.

\section{Consent for publication}

Not applicable.

\section{Competing interests}

The authors declare that they have no competing interests.

\section{Author details}

${ }^{1}$ Faculty Research Centre for Sport, Exercise \& Life Sciences, School of Health and Life Sciences, Coventry University, Coventry, UK. ${ }^{2} \mathrm{GO}$ fit LAB, Av. Islas de Filipinas, 7, 28003 Madrid, Spain. ${ }^{3}$ Observatory of Healthy \& Active Living, Spain Active Foundation, Centre for Sport Studies, King Juan Carlos University, Madrid, Spain. ${ }^{4}$ University of Rhode Island, Kingston, RI, USA. ${ }_{5}^{5}$ Advanced Wellbeing Research Centre, College of Health, Wellbeing and Life Sciences, Sheffield Hallam University, Sheffield, UK.

Received: 18 May 2020 Accepted: 20 October 2020

Published online: 10 November 2020

\section{References}

1. Hallal PC, Andersen LB, Bull FC, Guthold R, Haskell W, Ekelund U, et al. Global physical activity levels: surveillance progress, pitfalls, and prospects. Lancet. 2012;380(9838):247-57.

2. Mayo X, Del Villar F, Iglesias-Soler E, Liguori G, Mann S, Jimenez A. A retrospective analysis of policy development on compliance with World Health Organization's physical activity recommendations between 2002 and 2005 in European Union adults: closing the gap between research and policy. BMC Public Health. 2018;18(1):1081.

3. World Health Organization. Global recommendations on physical activity for health. Geneva: World Health Organization; 2010.

4. Guthold R, Stevens GA, Riley LM, Bull FC. Worldwide trends in insufficient physical activity from 2001 to 2016: a pooled analysis of 358 populationbased surveys with 1.9 million participants. Lancet Glob Health. 2018;6(10): e1077-86.

5. Sperling LS, Mechanick JI, Neeland IJ, Herrick CJ, Despres J-P, Ndumele CE, et al. The CardioMetabolic health Alliance: working toward a new care model for the metabolic syndrome. J Am Coll Cardiol. 2015;66(9):1050-67.

6. Organization WH. World health statistics 2018: monitoring health for the SDGs (sustainable development goals). Geneva: World Health Organization; 2018.

7. Engin A. The definition and prevalence of obesity and metabolic syndrome. In: Obesity and Lipotoxicity. Cham: Springer; 2017. p. 1-17.

8. Alberti K, Eckel RH, Grundy SM, Zimmet PZ, Cleeman Jl, Donato KA, et al. Harmonizing the metabolic syndrome: a joint interim statement of the international diabetes federation task force on epidemiology and prevention; national heart, lung, and blood institute; American heart association; world heart federation; international atherosclerosis society; and international association for the study of obesity. Circulation. 2009;120(16): 1640-5.

9. Fujiyoshi A, Murad MH, Luna M, Rosario A, Ali S, Paniagua D, et al. Metabolic syndrome and its components are underdiagnosed in cardiology clinics. J Eval Clin Pract. 2011;17(1):78-83.

10. Aguilar M, Bhuket T, Torres S, Liu B, Wong RJ. Prevalence of the metabolic syndrome in the United States, 2003-2012. JAMA. 2015;313(19):1973-4.
11. Mozumdar A, Liguori G. Persistent increase of prevalence of metabolic syndrome among US adults: NHANES III to NHANES 1999-2006. Diabetes Care. 2011;34(1):216-9.

12. Younis A, Younis A, Tzur B, Peled Y, Shlomo N, Goldenberg I, et al. Metabolic syndrome is independently associated with increased 20-year mortality in patients with stable coronary artery disease. Cardiovasc Diabetol. 2016;15(1):149.

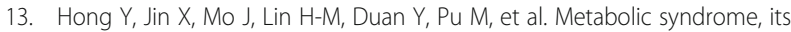
preeminent clusters, incident coronary heart disease and all-cause mortality-results of prospective analysis for the atherosclerosis risk in communities study. J Intern Med. 2007;262(1):113-22.

14. Koren-Morag N, Goldbourt U, Tanne D. Relation between the metabolic syndrome and ischemic stroke or transient ischemic attack: a prospective cohort study in patients with atherosclerotic cardiovascular disease. Stroke. 2005;36(7):1366-71.

15. Ursu O, Holmes J, Knockel J, Bologa CG, Yang JJ, Mathias SL, et al. DrugCentral: online drug compendium. Nucleic Acids Res. 2017;45(D1): D932-9.

16. Misselbeck K, Parolo S, Lorenzini F, Savoca V, Leonardelli L, Bora P, et al. A network-based approach to identify deregulated pathways and drug effects in metabolic syndrome. Nat Commun. 2019;10(1):5215.

17. Roberts SB, Dallal GE. Energy requirements and aging. Public Health Nutr. 2005;8(7a):1028-36.

18. Gakidou E, Afshin A, Abajobir AA, Abate KH, Abbafati C, Abbas KM, et al. Global, regional, and national comparative risk assessment of 84 behavioural, environmental and occupational, and metabolic risks or clusters of risks, 1990-2016: a systematic analysis for the global burden of disease study 2016. Lancet. 2017;390(10100):1345-422.

19. Ross R, Blair SN, Arena R, Church TS, Després J-P, Franklin BA, et al. Importance of assessing cardiorespiratory fitness in clinical practice: a case for fitness as a clinical vital sign: a scientific statement from the American Heart Association. Circulation. 2016;134(24):e653-99.

20. Salonen MK, Wasenius N, Kajantie E, Lano A, Lahti J, Heinonen K, et al. Physical activity, body composition and metabolic syndrome in young adults. PloS one. 2015;10(5):e0126737. https://doi.org/10.1371/journal.pone. 0126737.

21. Bird SR, Hawley JA. Update on the effects of physical activity on insulin sensitivity in humans. BMJ Open Sport Exerc Med. 2017;2(1):e000143.

22. Saklayen MG. The global epidemic of the metabolic syndrome. Curr Hypertens Rep. 2018;20(2):12.

23. Sharifi N, Mahdavi R, Ebrahimi-Mameghani M. Perceived barriers to weight loss programs for overweight or obese women. Health Promot Perspect 2013;3(1):11

24. Gibala MJ. High-intensity interval training: a time-efficient strategy for health promotion? Curr Sports Med Rep. 2007;6(4):211-3.

25. Burgomaster KA, Howarth KR, Phillips SM, Rakobowchuk M, MacDonald MJ, McGee SL, et al. Similar metabolic adaptations during exercise after low volume sprint interval and traditional endurance training in humans. J Physiol. 2008;586(1):151-60.

26. Gibala MJ, Little JP, Van Essen M, Wilkin GP, Burgomaster KA, Safdar A, et al. Short-term sprint interval versus traditional endurance training: similar initial adaptations in human skeletal muscle and exercise performance. J Physiol. 2006;575(3):901-11.

27. Biddle SJ, Batterham AM. High-intensity interval exercise training for public health: a big HIT or shall we HIT it on the head? Int J Behav Nutr Phys Act. 2015;12(1):95

28. Levinger I, Shaw CS, Stepto NK, Cassar S, McAinch AJ, Cheetham C, et al. What doesn't kill you makes you fitter: a systematic review of high-intensity interval exercise for patients with cardiovascular and metabolic diseases. Clin Med Insights Cardiol. 2015;9. https://doi.org/10.4137/CMC.S26230.

29. Hannan AL, Hing W, Simas V, Climstein M, Coombes JS, Jayasinghe R, et al. High-intensity interval training versus moderate-intensity continuous training within cardiac rehabilitation: a systematic review and meta-analysis. Open Access J Sports Med. 2018;9:1-17.

30. Wewege MA, Ahn D, Yu J, Liou K, Keech A. High-Intensity Interval Training for Patients With Cardiovascular Disease-Is It Safe? A Systematic Review. J Am Heart Assoc. 2018;7(21):e009305.

31. Hwang C-L, Yoo J-K, Kim H-K, Hwang M-H, Handberg EM, Petersen JW, et al. Novel all-extremity high-intensity interval training improves aerobic fitness, cardiac function and insulin resistance in healthy older adults. Exp Gerontol. 2016;82:112-9. 
32. Sculthorpe NF, Herbert P, Grace F. One session of high-intensity interval training (HIIT) every 5 days, improves muscle power but not static balance in lifelong sedentary ageing men: a randomized controlled trial. Medicine (Baltimore). 2017:96(6):e6040.

33. Oliveira BRR, Santos TM, Kilpatrick M, Pires FO, Deslandes AC. Affective and enjoyment responses in high intensity interval training and continuous training: A systematic review and meta-analysis. PLoS One. 2018;13(6): e019712. https://doi.org/10.1371/journal.pone.0197124.

34. De Nardi AT, Tolves T, Lenzi TL, Signori LU, da Silva AMV. High-intensity interval training versus continuous training on physiological and metabolic variables in prediabetes and type 2 diabetes: a meta-analysis. Diabetes Res Clin Pract. 2018;137:149-59.

35. Dun Y, Thomas RJ, Smith JR, Medina-Inojosa JR, Squires RW, Bonikowske AR, et al. High-intensity interval training improves metabolic syndrome and body composition in outpatient cardiac rehabilitation patients with myocardial infarction. Cardiovasc Diabetol. 2019;18(1):104.

36. Weston KS, Wisløff U, Coombes JS. High-intensity interval training in patients with lifestyle-induced cardiometabolic disease: a systematic review and meta-analysis. Br J Sports Med. 2014;48(16):1227-34.

37. Moher D, Liberati A, Tetzlaff J, Altman DG. Preferred reporting items for systematic reviews and meta-analyses: the PRISMA statement. Ann Intern Med. 2009;151(4):264-9.

38. Higgins JP, Altman DG, Gøtzsche PC, Jüni $P$, Moher D, Oxman AD, et al. The Cochrane Collaboration's tool for assessing risk of bias in randomised trials. BMJ. 2011;343:d5928.

39. Verhagen AP, de Vet HC, de Bie RA, Kessels AG, Boers M, Bouter LM, et al. The Delphi list: a criteria list for quality assessment of randomized clinical trials for conducting systematic reviews developed by Delphi consensus. J Clin Epidemiol. 1998;51(12):1235-41.

40. Valkenet $\mathrm{K}$, van de Port IGL, Dronkers JJ, de Vries WR, Lindeman E, BackX FJG. The effects of preoperative exercise therapy on postoperative outcome: a systematic review. Clin Rehabil. 2011;25(2):99-111.

41. Orwin RG, Vevea JL. Evaluating coding decisions. Handb Res Synth Meta Anal. 2009;2:177-203.

42. Borenstein M, Hedges LV, Higgins JP, Rothstein HR. Introduction to metaanalysis. Chichester: Wiley; 2011

43. Sánchez-Meca J, Marín-Martínez F. Confidence intervals for the overall effect size in random-effects meta-analysis. Psychol Methods. 2008;13(1):31.

44. Alvarez C, Ramirez-Campillo R, Martinez-Salazar C, Castillo A, Gallardo F, Ciolac EG. High-intensity interval training as a tool for counteracting dyslipidemia in women. Int J Sports Med. 2018;39(05):397-406.

45. Morales-Palomo F, Ramirez-Jimenez M, Ortega JF, Lopez-Galindo PL, Fernandez-Martin J, Mora-Rodriguez R. Effects of repeated yearly exposure to exercise-training on blood pressure and metabolic syndrome evolution. J Hypertens. 2017;35(10):1992-9.

46. Morales-Palomo F, Ramirez-Jimenez M, Ortega JF, Mora-Rodriguez R. Effectiveness of aerobic exercise programs for health promotion in metabolic syndrome. Med Sci Sports Exerc. 2019;51(9):1876-83.

47. Mora-Rodriguez R, Fernandez-Elias VE, Morales-Palomo F, Pallares JG, Ramirez-Jimenez M, Ortega JF. Aerobic interval training reduces vascular resistances during submaximal exercise in obese metabolic syndrome individuals. Eur J Appl Physiol. 2017;117(10):2065-73.

48. Mora-Rodriguez R, Ortega J, Morales-Palomo F, Ramirez-Jimenez M. Weight loss but not gains in cardiorespiratory fitness after exercise-training predicts improved health risk factors in metabolic syndrome. Nutr Metab Cardiovasc Dis. 2018;28(12):1267.

49. Mora-Rodriguez R, Ramirez-Jimenez M, Fernandez-Elias VE, Guio de Prada MV, Morales-Palomo F, Pallares JG, et al. Effects of aerobic interval training on arterial stiffness and microvascular function in patients with metabolic syndrome. J Clin Hypertens. 2018;20(1):11-8.

50. Mora-Rodriguez R, Ortega JF, Ramirez-Jimenez M, Moreno-Cabañas A Morales-Palomo F. Insulin sensitivity improvement with exercise training is mediated by body weight loss in subjects with metabolic syndrome. Diabetes Metab. 2019:46(3):210-18.

51. Stensvold D, Tjønna AE, Skaug E-A, Aspenes S, Stølen T, Wisløff U, et al. Strength training versus aerobic interval training to modify risk factors of metabolic syndrome. J Appl Physiol. 2010;108(4):804-10.

52. Tjønna AE, Lee SJ, Rognmo Ø, Stølen TO, Bye A, Haram PM, et al. Aerobic interval training versus continuous moderate exercise as a treatment for the metabolic syndrome: a pilot study. Circulation. 2008;118(4):346-54.
53. Sari-Sarraf V, Aliasgarzadeh A, Naderali M-M, Esmaeili H, Naderali EK. A combined continuous and interval aerobic training improves metabolic syndrome risk factors in men. Int J Gen Med. 2015;8:203-10.

54. Röhling M, Herder C, Stemper T, Müssig K. Influence of acute and chronic exercise on glucose uptake. J Diabetes Res. 2016;2016:2868652.

55. Christ-Roberts CY, Pratipanawatr T, Pratipanawatr W, Berria R, Belfort R, Kashyap $\mathrm{S}$, et al. Exercise training increases glycogen synthase activity and GLUT4 expression but not insulin signaling in overweight nondiabetic and type 2 diabetic subjects. Metab Clin Exp. 2004;53(9):1233-42.

56. Whyte $L$, Gill JMR, Cathcart AJ. Effect of 2 weeks of sprint interval training on health-related outcomes in sedentary overweight/obese men. Metab Clin Exp. 2010;59(10):1421-8.

57. Little JP, Jung ME, Wright AE, Wright W, Manders RJF. Effects of highintensity interval exercise versus continuous moderate-intensity exercise on postprandial glycemic control assessed by continuous glucose monitoring in obese adults. Appl Physiol Nutr Metab. 2014;39(7):835-41.

58. Gibala MJ, McGee SL. Metabolic adaptations to short-term high-intensity interval training: a little pain for a lot of gain? Exerc Sport Sci Rev. 2008; 36(2):58-63.

59. Nakhanakhup C, Moungmee P, Appell HJ, Duarte JA. Regular physical exercise in patients with type II diabetes mellitus. Eur Rev Aging Phys Act Act. 2006;3(1):10

60. Sallis JF, Bull F, Guthold R, Heath GW, Inoue S, Kelly P, et al. Progress in physical activity over the Olympic quadrennium. Lancet. 2016;388(10051): 1325-36.

61. Su L, Fu J, Sun S, Zhao G, Cheng W, Dou C, et al. Effects of HIIT and MICT on cardiovascular risk factors in adults with overweight and/or obesity: a meta-analysis. PLoS One. 2019;14(1):e0210644.

62. Cook NR, Cohen J, Hebert PR, Taylor JO, Hennekens CH. Implications of small reductions in diastolic blood pressure for primary prevention. Arch Intern Med. 1995;155(7):701-9.

63. Millar PJ, McGowan CL, Cornelissen VA, Araujo CG, Swaine IL. Evidence for the role of isometric exercise training in reducing blood pressure: potential mechanisms and future directions. Sports Med. 2014:44(3):345-56.

64. Turnbull F. Blood pressure lowering treatment Trialists' collaboration. Effects of different blood-pressure-lowering regimens on major cardiovascular events: results of prospectively-designed overviews of randomised trials. Lancet. 2003;362(9395):1527-35.

65. Ghadieh AS, Saab B. Evidence for exercise training in the management of hypertension in adults. Coll Fam Physicians Can. 2015;61(3):233-9.

66. Pescatello LS, Franklin BA, Fagard R, Farquhar WB, Kelley GA, Ray CA, et al. American College of Sports Medicine position stand. Exercise and hypertension. Med Sci Sports Exerc. 2004;36(3):533-53.

67. Tipton CM. Exercise, training, and hypertension. Exerc Sport Sci Rev. 1984;12: 245-306.

68. Cornelissen VA, Fagard RH, Coeckelberghs E, Vanhees L. Impact of resistance training on blood pressure and other cardiovascular risk factors: a metaanalysis of randomized, controlled trials. Hypertension. 2011;58(5):950-8.

69. Cornelissen VA, Buys R, Smart NA. Endurance exercise beneficially affects ambulatory blood pressure: a systematic review and meta-analysis. J Hypertens. 2013;31(4):639-48.

70. North American Association for the Study of Obesity, National Heart, Lung, Blood Institute, NHLBI Obesity Education Initiative. The practical guide: identification, evaluation, and treatment of overweight and obesity in adults. Bethesda: National Institutes of Health, National Heart, Lung, and Blood Institute; 2000

71. Matsuzawa Y, Shimomura I, Nakamura T, Keno Y, Kotani K, Tokunaga K. Pathophysiology and pathogenesis of visceral fat obesity. Obes Res. 1995; 3(S2):187s-94s.

72. Boutcher SH. High-intensity intermittent exercise and fat loss. J Obes. 2011; 2011:868305. https://doi.org/10.1155/2011/868305.

73. Laforgia J, Withers RT, Gore CJ. Effects of exercise intensity and duration on the excess post-exercise oxygen consumption. J Sports Sci. 2006;24(12):1247-64.

74. Gaitanos GC, Williams C, Boobis LH, Brooks S. Human muscle metabolism during intermittent maximal exercise. J Appl Physiol. 1993;75(2):712-9.

75. Afrasyabi S, Marandi SM, Kargarfard M. The effects of high intensity interval training on appetite management in individuals with type 2 diabetes: influenced by participants weight. J Diabetes Metab Disord. 2019;18(1):107-17.

76. Wewege M, Van Den Berg R, Ward R, Keech A. The effects of high-intensity interval training vs. moderate-intensity continuous training on body 
composition in overweight and obese adults: a systematic review and meta-analysis. Obes Rev. 2017;18(6):635-46.

77. Wood G, Murrell A, van der Touw T, Smart N. HIIT is not superior to MICT in altering blood lipids: a systematic review and meta-analysis. BMJ Open Sport Exerc Med. 2019;5(1):e000647. https://doi.org/10.1136/bmjsem-2019000647

78. Parfitt $\mathrm{G}$, Hughes $\mathrm{S}$. The exercise intensity-affect relationship: evidence and implications for exercise behavior. J Exerc Sci Fit. 2009;7(2):S34-41.

79. Roloff ZA, Dicks ND, Krynski LM, Hartman ME, Ekkekakis P, Pettitt RW. Ratings of affective valence closely track changes in oxygen uptake: Application to high-intensity interval exercise. Perform Enhancement Health. 2020;7(3):100158.

80. Bottoms L, Leighton D, Carpenter R, Anderson S, Langmead L, Ramage J, et al. Affective and enjoyment responses to 12 weeks of high intensity interval training and moderate continuous training in adults with Crohn's disease. PLoS One. 2019;14(9):e0222060. https://doi.org/10.1371/journal. pone.0222060.

81. Thum JS, Parsons G, Whittle T, Astorino TA. High-intensity interval training elicits higher enjoyment than moderate intensity continuous exercise. PLoS One. 2017;12(1):e0166299. https://doi.org/10.1371/journal.pone.0166299.

82. Vella CA, Taylor K, Drummer D. High-intensity interval and moderateintensity continuous training elicit similar enjoyment and adherence levels in overweight and obese adults. Eur J Sport Sci. 2017;17(9):1203-11.

83. Heisz JJ, Tejada MGM, Paolucci EM, Muir C. Enjoyment for high-intensity interval exercise increases during the first six weeks of training: implications for promoting exercise adherence in sedentary adults. PLoS One. 2016; 11(12):e0168534. https://doi.org/10.1371/journal.pone.0168534.

\section{Publisher's Note}

Springer Nature remains neutral with regard to jurisdictional claims in published maps and institutional affiliations.

Ready to submit your research? Choose BMC and benefit from:

- fast, convenient online submission

- thorough peer review by experienced researchers in your field

- rapid publication on acceptance

- support for research data, including large and complex data types

- gold Open Access which fosters wider collaboration and increased citations

- maximum visibility for your research: over $100 \mathrm{M}$ website views per year

At $\mathrm{BMC}$, research is always in progress.

Learn more biomedcentral.com/submissions 